\title{
Rituximab-Based Treatment, HCV Replication, and Hepatic Flares
}

\section{Evangelista Sagnelli, ${ }^{1,2}$ Mariantonietta Pisaturo, ${ }^{1,2}$ Caterina Sagnelli, ${ }^{3}$ and Nicola Coppola ${ }^{1}$}

\author{
${ }^{1}$ Section of Infectious Diseases, Department of Public Medicine, Second University of Naples, 80131 Naples, Italy \\ ${ }^{2}$ Division of Infectious Diseases, AORN Sant'Anna e San Sebastiano di Caserta, 81100 Caserta, Italy \\ ${ }^{3}$ Department of Clinical and Experimental Medicine and Surgery "F. Magrassi e A. Lanzara", \\ Second University of Naples, 80131 Naples, Italy
}

Correspondence should be addressed to Evangelista Sagnelli, evangelista.sagnelli@unina2.it

Received 26 April 2012; Accepted 20 June 2012

Academic Editor: Jürg Schifferli

\begin{abstract}
Copyright (C) 2012 Evangelista Sagnelli et al. This is an open access article distributed under the Creative Commons Attribution License, which permits unrestricted use, distribution, and reproduction in any medium, provided the original work is properly cited.

Rituximab, a chimeric mouse-human monoclonal antibody directed to the CD20 antigen expressed on pre-B lymphocytes and mature lymphocytes, causes a profound B-cell depletion. Due to its peculiar characteristics, this drug has been used to treat oncohaematological diseases, B cell-related autoimmune diseases, rheumatoid arthritis, and, more recently, HCV-associated mixed cryoglobulinaemic vasculitis. Rituximab-based treatment, however, may induce an increased replication of several viruses such as hepatitis B virus, cytomegalovirus, varicella-zoster virus, echovirus, and parvovirus B19. Recent data suggest that rituximab-based chemotherapy induces an increase in HCV expression in hepatic cells, which may become a target for a cell-mediated immune reaction after the withdrawal of treatment and the restoration of the immune control. Only a few small studies have investigated the occurrence of HCV reactivation and an associated hepatic flare in patients with oncohaematological diseases receiving RCHOP (rituximab, cyclophosphamide, doxorubicin, vincristine, and prednisone). These studies suggest that the hepatic flares are frequently asymptomatic, but life-threatening liver failure occurs in nearly $10 \%$ of cases.
\end{abstract}

\section{Introduction}

Hepatitis $\mathrm{C}$ virus (HCV) is responsible worldwide for chronic hepatitis, liver cirrhosis, and hepatocellular carcinoma [1]. Besides its hepatotropic characteristics, HCV is also a lymphotropic virus [2,3] responsible for HCV-related B-cell non-Hodgkin lymphoma (NHL) [4-6], immune-mediated extrahepatic manifestations, mixed cryoglobulinaemic vasculitis [7-12], and the presence in serum of rheumatoid factor and autoantibodies [13-15].

In the last decade, rituximab, a chimeric mouse-human monoclonal antibody directed to the CD20 antigen expressed on pre-B lymphocytes and mature lymphocytes [16], has been used increasingly for treating patients with haematological diseases including CD20-positive B-cell NHL [17]. Rituximab causes a profound B-cell depletion, peripheral blood B lymphocytes becoming undetectable after a single infusion, with a complete B-cell recovery from 6 to 9 months after the discontinuation of treatment $[18,19]$. Due to its peculiar characteristics, this drug has also been used for treating B cell-related autoimmune diseases [20], rheumatoid arthritis, and, more recently, HCV-associated mixed cryoglobulinaemic vasculitis $[21,22]$.

It is well known that rituximab-based chemotherapy is frequently followed by a reactivation of viral infections and correlated diseases. A frequent increase in viral replication under R-CHOP (rituximab, cyclophosphamide, doxorubicin, vincristine, and prednisone) was demonstrated by Aksoy et al. for several viruses including hepatitis B virus (HBV), cytomegalovirus, varicella-zoster virus, echovirus, and parvovirus B19 [23]. Worthy of mention is HBV infection, both overt and occult, which in the absence of a specific prophylaxis or treatment frequently reactivates during or after R-CHOP, with a mortality rate close to $20 \%$ and death 
being due to liver failure or to an unfavourable progression of the underlying haematological disease once R-CHOP has been discontinued because of a hepatic flare [24-33].

\subsection{Studies on HCV Reactivation and Hepatic Flares due to} Rituximab-Based Chemotherapy. According to the fragmentar data available, R-CHOP can induce an increase in HCV replication in oncohaematological patients $[34,35]$, a biological event associated to the development of hepatic flares in some studies [36-41]. A reasonable explanation for this association may be that R-CHOP induces an increase in HCV expression in hepatic cells, which may become a target for a cell-mediated immune reaction after the discontinuation of treatment and the restoration of the immune control. This hypothesis, however, requires support from further studies with a longer follow up to clarify the relationship between $\mathrm{HCV}$ reactivation and the occurrence of a hepatic flare and to assess the clinical impact of flares.

The uncertainty dominating this topic arises from the inconsistent data available and from the marked differences in the studies as regards the design, age of the patients, type and stage of the oncohaematological diseases, type of chemotherapy used, and stage of liver disease. In addition, the criteria used to define HCV reactivation and a hepatic flare differ from study to study.

Some of these papers are case reports. Akosy et al. described HCV reactivation not associated to a hepatic flare in a patient with HCV-related cirrhosis and NHL treated only with rituximab [34]. Nooka et al. published a similar observation in a patient with diffuse large B-cell lymphoma (DLBCL) and HCV infection who experienced an asymptomatic $\mathrm{HCV}$ reactivation during R-CHOP [35]. Hsieh et al. described an HCV reactivation with a hepatic flare in a patient with DLBCL receiving R-CHOP [41], and LakeBakaar reported a case of $\mathrm{HCV}$ reactivation in a patient with HCV-related mixed cryoglobulinaemia who developed a hepatic flare 2 weeks after starting rituximab treatment [42].

Only a few studies evaluated both HCV reactivation and the development of a hepatic flare in small series of patients with oncohaematological diseases receiving $\mathrm{R}$ $\mathrm{CHOP}$ (Table 1). In a prospective study on 8 anti-HCV/HCV RNA-positive patients undergoing chemotherapy, HCV replication was determined both in plasma and peripheral blood mononuclear cells (PBMC). In this study, Coppola et al. [40] found an increase in HCV RNA of at least $1.5 \mathrm{log}$ $\mathrm{IU} / \mathrm{mL}$ in plasma and of at least $1.1 \mathrm{log} \mathrm{IU} / \mathrm{mL}$ in PBMC of the 7 patients receiving rituximab and corticosteroid-based chemotherapy, whereas no change was observed in the one patient treated with rituximab-sparing chemotherapy. In this study, the patients with HCV reactivation showed a hepatic flare 3-5 months after treatment was discontinued; this was life threatening only in one patient who had compensated cirrhosis at the baseline and developed a grade- 3 hepatic flare, ascites, and portosystemic encephalopathy with a progression of Child-Pugh score from A6 to B9 (Table 1).

In a retrospective study on 131 patients with $\mathrm{HCV}$ infection and NHL treated with rituximab and prednisone-based chemotherapy, Ennishi et al. [36] described a hepatic flare in 36 patients (27\%), of these 131, 34 with DLBCL showed HCV reactivation during the follow up, but the prevalence of hepatic flares in these 34 patients was not reported (Table 1). In nearly $10 \%$ of cases, the hepatic flares were life threatening and some patients died of liver failure. The retrospective nature of the study, however, suggests caution in accepting these data as conclusive.

In a retrospective study, Marignani et al. [39] described 3 patients with HCV infection and NHL treated with R-CHOP therapy. Two of these patients experienced HCV reactivation and showed a hepatic flare, which was symptomatic in one of the two, after chemotherapy was discontinued (Table 1). This patient showed an increase in serum total bilirubin up to $7.8 \mathrm{mg} / \mathrm{dL}$ and became asymptomatic in 4 weeks. The third patient did not show an HCV reactivation but developed a hepatic flare after chemotherapy was discontinued.

Pitini et al. recently described HCV reactivation and a hepatic flare in 10 patients with HCV infection and NHL treated with R-CHOP [38]. The hepatic flare was asymptomatic in 8 and symptomatic in 2 patients (Table 1): a 68year-old male with DLBCL who developed HCV reactivation and a hepatic flare two weeks after the third cycle of RCHOP and died of acute liver failure and a 65-year-old female with DLBCL who developed severe ascitis after four cycles of R-CHOP and died 1 week later for the uncontrolled progression of the underlying oncohaematological disease.

Similar results were reported by Tsutsumi et al. [37] in a prospective study of 4 patients with HCV infection and NHL treated with R-CHOP; all patients showed HCV reactivation and a hepatic flare during chemotherapy, but no severe clinical events occurred (Table 1).

In a retrospective study on 160 patients with Hodgkin's lymphoma and HCV infection, Arcaini et al. described hepatotoxicity in $5(17.9 \%)$ of 28 patients with B-cell lymphoma treated with R-CHOP [43]. For 25 patients in this study, 15 treated with R-CHOP and 10 with $\mathrm{CHOP}$, circulating HCV RNA was quantified at each cycle of chemotherapy; HCVRNA quantification did not correlate to liver toxicity.

Petrarca et al. treated HCV-associated mixed cryoglobulinaemia with rituximab and found this treatment useful and safe even in patients with a severe liver disease [44]; the patients in this study, however, had a low degree of immune depression and did not receive corticosteroids.

Worthy of mention is the literature showing a frequent occurrence of hepatic flares in patients receiving high-dose corticosteroids plus rituximab [36-40], probably because of a cumulative effect of these drugs, which both induce an increase in HCV replication, rituximab because of the impairment of antibody production, $[18,19,45]$ and corticosteroids because of the enhancement of HCV entry to the hepatocytes as a consequence of an overexpression of specific receptors on the surface of these cells $[46,47]$.

1.2. Other Studies. Visco et al. reported an association between R-CHOP treatment for DLBCL and a mild increase in the liver enzyme level not requiring discontinuation of treatment in 5 (14\%) of 35 patients [48]; this study, however, gave no information on HCV reactivation. 


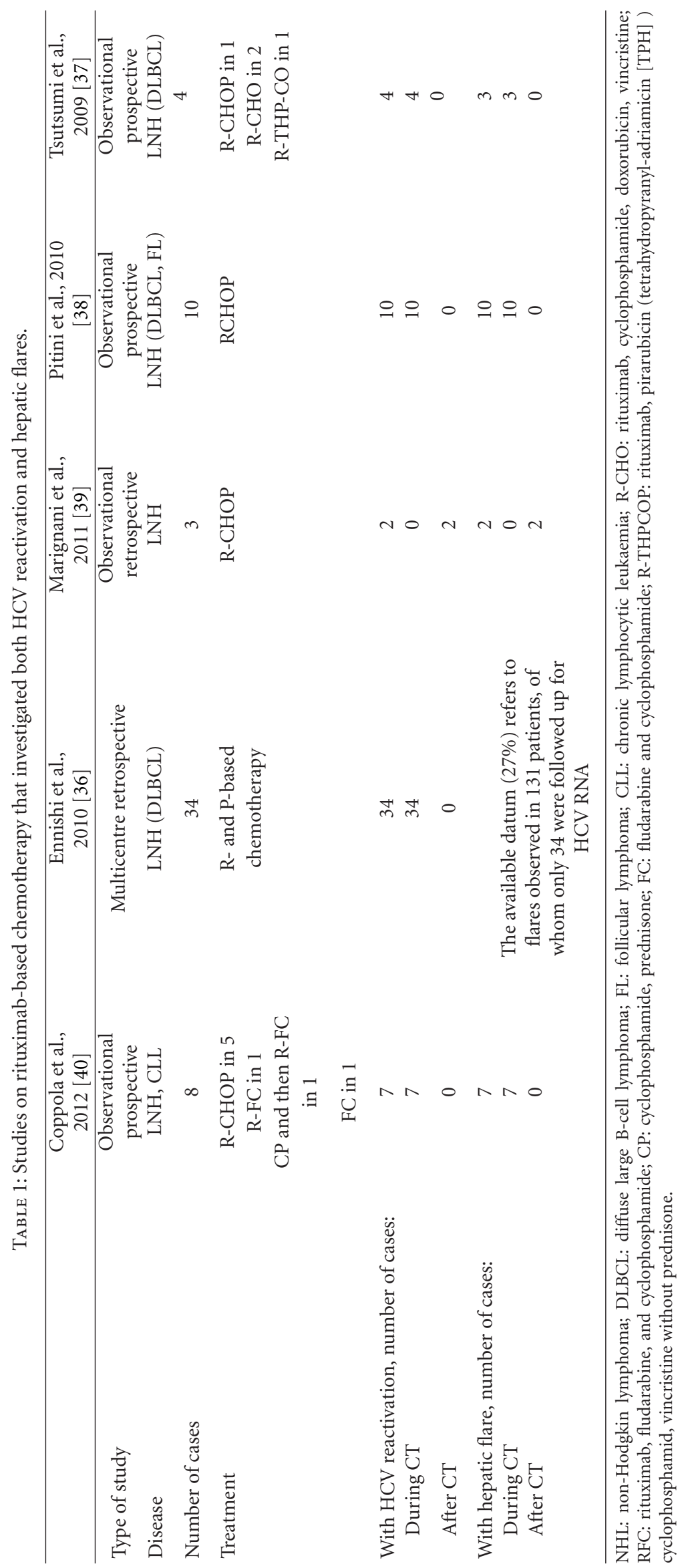


Coppola et al. described 28 anti-HCV/HCV RNA-negative patients receiving chemotherapy (rituximab based in $61 \%$ of cases) for oncohaematological diseases. These patients remained HCV RNA-negative both in plasma and PBMC and no hepatic flare was observed over an observation period of 6-24 months [49], most probably because no patient in this study had an occult HCV infection.

\section{Conclusions}

Fragmentary information from case reports, small studies, and retrospective investigations suggest, on the whole, that rituximab-based chemotherapy favours viral replication in patients with HCV infection and oncohaematological diseases. Only a few small studies evaluated both variations in the HCV viral load and the development of a hepatic flare during or after R-CHOP treatment, but the results are concordant and strongly suggest a close association between these two events. A possible interpretation of this association is that R-CHOP induces an enhancement of HCV replication followed by a spontaneous subsequent decrease once treatment is reduced or discontinued. The consequent restoration of the immune control may induce a hepatic flare of varying clinical impact, that is, asymptomatic, symptomatic or life threatening, most probably reflecting the extent of cellmediated hepatocellular necrosis. The clinical effects seem more evident in patients treated with a combination of rituximab and high-dose corticosteroids.

The high prevalence worldwide of $\mathrm{HCV}$ infection in oncohaematological patients and the progressive increase in the use of R-CHOP for treating these diseases may create a heavy burden in the future for the health care authorities in several countries.

\section{Acknowledgments}

This study was supported by a grant from PRIN 2008, M.I.U.R., Rome, Italy "ottimizzazione della diagnosi eziologica dell'epatite acuta c e studio dei fattori viro-immunologici di guarigione, di cronicizzazione e di risposta alla terapia con interferone" and in part by a grant from Regione Campania "Progetti per il miglioramento della qualità dell'assistenza, diagnosi e terapia del paziente affetto da AIDS nei settori: immunologia, coinfezioni, informazione e prevenzione 2008 ".

\section{References}

[1] J. El Hoofnagle and T. S. Tralka, "Introduction: The National Institutes of Health Consensus Development Conference: management of hepatitis C virus," Hepatology, vol. 26, no. 3, supplement, pp. 1S-2S, 1997.

[2] A. L. Zignego, D. Macchia, M. Monti et al., "Infection of peripheral mononuclear blood cells by hepatitis C virus," Journal of Hepatology, vol. 15, no. 3, pp. 382-386, 1992.

[3] A. L. Zignego, C. Giannini, M. Monti, and L. Gragnani, "Hepatitis $\mathrm{C}$ virus lymphotropism: lessons from a decade of studies," Digestive and Liver Disease, vol. 39, no. 1, pp. S38-S45, 2007.
[4] C. Ferri, F. Caracciolo, A. L. Zignego et al., "Hepatitis C virus infection in patients with non-Hodgkin's lymphoma," British Journal of Haematology, vol. 88, no. 2, pp. 392-394, 1994.

[5] F. Silvestri, C. Pipan, G. Barillari et al., "Prevalence of hepatitis $\mathrm{C}$ virus infection in patients with lymphoproliferative disorders," Blood, vol. 87, no. 10, pp. 4296-4301, 1996.

[6] E. Zuckerman, T. Zuckerman, A. M. Levine et al., "Hepatitis $\mathrm{C}$ virus infection in patients with B-cell non-Hodgkin lymphoma," Annals of Internal Medicine, vol. 127, no. 6, pp. 423428, 1997.

[7] R. Misiani, P. Bellavita, D. Fenili et al., "Hepatitis C virus infection in patients with essential mixed cryoglobulinemia," Annals of Internal Medicine, vol. 117, no. 7, pp. 573-577, 1992.

[8] V. Agnello, R. T. Chung, and L. M. Kaplan, "A role for hepatitis C virus infection in Type II cryoglobulinemia," New England Journal of Medicine, vol. 327, no. 21, pp. 1490-1495, 1992.

[9] P. Marcellin, V. Descamps, M. Martinot-Peignoux et al., "Cryoglobulinemia with vasculitis associated with hepatitis C virus infection," Gastroenterology, vol. 104, no. 1, pp. 272-277, 1993.

[10] J. Haddad, P. Deny, C. Munz-Gotheil et al., "Lymphocytic sialadenitis of Sjogren's syndrome associated with chronic hepatitis C virus liver disease," The Lancet, vol. 339, no. 8789, pp. 321-323, 1992.

[11] J. M. Pawlotsky, F. Roudot-Thoraval, P. Simmonds et al., "Extrahepatic immunologic manifestations in chronic hepatitis C and hepatitis C virus serotypes," Annals of Internal Medicine, vol. 122, no. 3, pp. 169-173, 1995.

[12] S. C. Gumber and S. Chopra, "Hepatitis C: a multifaceted disease. Review of extrahepatic manifestations," Annals of Internal Medicine, vol. 123, no. 8, pp. 615-620, 1995.

[13] S. J. Hadziyannis, "The spectrum of extrahepatic manifestations in hepatitis C virus infection," Journal of Viral Hepatitis, vol. 4, no. 1, pp. 9-28, 1997.

[14] B. D. Clifford, D. Donahue, L. Smith et al., "High prevalence of serological markers of autoimmunity in patients with chronic hepatitis C," Hepatology, vol. 21, no. 3, pp. 613-619, 1995.

[15] J. Prieto, J. R. Yuste, O. Beloqui et al., "Anticardiolipin antibodies in chronic hepatitis C: implication of hepatitis $\mathrm{C}$ virus as the cause of the antiphospholipid syndrome," Hepatology, vol. 23, no. 2, pp. 199-204, 1996.

[16] P. Stashenko, L. M. Nadler, R. Hardy, and S. F. Schlossman, "Characterization of a human B lymphocyte-specific antigen," Journal of Immunology, vol. 125, no. 4, pp. 1678-1685, 1980.

[17] B. D. Cheson, "CHOP plus rituximab-balancing facts and opinion," New England Journal of Medicine, vol. 346, no. 4, pp. 280-282, 2002.

[18] M. E. Reff, K. Carner, K. S. Chambers et al., "Depletion of B cells in vivo by a chimeric mouse human monoclonal antibody to CD20," Blood, vol. 83, no. 2, pp. 435-445, 1994.

[19] P. McLaughlin, A. J. Grillo-López, B. K. Link et al., "Rituximab chimeric anti-CD20 monoclonal antibody therapy for relapsed indolent lymphoma: half of patients respond to a four-dose treatment program," Journal of Clinical Oncology, vol. 16, no. 8, pp. 2825-2833, 1998.

[20] D. E. Furst, F. C. Breedveld, J. R. Kalden et al., "Updated consensus statement on biological agents for the treatment of rheumatic diseases, 2007," Annals of the Rheumatic Diseases, vol. 66, supplement 3, pp. iii2-iii22, 2007.

[21] P. Cacoub, A. Delluc, D. Saadoun, D. A. Landau, and D. Sene, "Anti-CD20 monoclonal antibody (rituximab) treatment for cryoglobulinemia vasculitis: where do we stand?" Annals of the Rheumatic Diseases, vol. 67, no. 3, pp. 283-287, 2008.

[22] D. Saadoun, M. Rosenzwajg, D. Landau, J. C. Piette, D. Klatzmann, and P. Cacoub, "Restoration of peripheral immune 
homeostasis after rituximab in mixed cryoglobulinemia vasculitis," Blood, vol. 111, no. 11, pp. 5334-5341, 2008.

[23] S. Aksoy, H. Harputluoglu, S. Kilickap et al., "Rituximab-related viral infections in lymphoma patients," Leukemia and Lymphoma, vol. 48, no. 7, pp. 1307-1312, 2007.

[24] W. Yeo and P. J. Johnson, "Diagnosis, prevention and management of hepatitis B virus reactivation during anticancer therapy," Hepatology, vol. 43, no. 2, pp. 209-220, 2006.

[25] R. Loomba, A. Rowley, R. Wesley et al., "Systematic review: the effect of preventive lamivudine on hepatitis B reactivation during chemotherapy," Annals of Internal Medicine, vol. 148, no. 7, pp. 519-528, 2008.

[26] C. Hsu, C. A. Hsiung, I. J. Su et al., "A revisit of prophylactic lamivudine for chemotherapy-associated hepatitis B reactivation in non-Hodgkin's lymphoma: a randomized trial," Hepatology, vol. 47, no. 3, pp. 844-853, 2008.

[27] T. N. Palmore, N. L. Shah, R. Loomba et al., "Reactivation of hepatitis B with reappearance of hepatitis B surface antigen after chemotherapy and immunosuppression," Clinical Gastroenterology and Hepatology, vol. 7, no. 10, pp. 1130-1137, 2009.

[28] N. Fukushima, T. Mizuta, M. Tanaka et al., "Retrospective and prospective studies of hepatitis B virus reactivation in malignant lymphoma with occult HBV carrier," Annals of Oncology, vol. 20, no. 12, pp. 2013-2017, 2009.

[29] W. Yeo, T. C. Chan, N. W. Y. Leung et al., "Hepatitis B virus reactivation in lymphoma patients with prior resolved hepatitis B undergoing anticancer therapy with or without rituximab," Journal of Clinical Oncology, vol. 27, no. 4, pp. 605-611, 2009.

[30] S. N. Pei, C. H. Chen, C. M. Lee et al., "Reactivation of hepatitis B virus following rituximab-based regimens: a serious complication in both HBsAg-positive and HBsAgnegative patients," Annals of Hematology, vol. 89, no. 3, pp. 255-262, 2010.

[31] Y. X. Koo, D. S. W. Tan, I. B. Tan, M. Tao, W. C. Chow, and S. T. Lim, "Hepatitis B virus reactivation and role of antiviral prophylaxis in lymphoma patients with past hepatitis B virus infection who are receiving chemoimmunotherapy," Cancer, vol. 116, no. 1, pp. 115-121, 2010.

[32] A. Marzano, E. Angelucci, P. Andreone et al., "Prophylaxis and treatment of hepatitis B in immunocompromised patients," Digestive and Liver Disease, vol. 39, no. 5, pp. 397-408, 2007.

[33] N. Coppola, G. Tonziello, M. Pisaturo et al., "Reactivation of overt and occult hepatitis B infection in various immunosuppressive settings," Journal of Medical Virology, vol. 83, no. 11, pp. 1909-1916, 2011.

[34] S. Aksoy, H. Abali, S. Kilickap, M. Erman, and A. Kars, "Accelerated hepatitis $\mathrm{C}$ virus replication with rituximab treatment in a non-Hodgkin's lymphoma patient," Clinical and Laboratory Haematology, vol. 28, no. 3, pp. 211-214, 2006.

[35] A. Nooka, P. J. Shenoy, R. Sinha, S. Lonial, and C. R. Flowers, "Hepatitis $\mathrm{C}$ reactivation in patients who have diffuse large B-cell lymphoma treated with rituximab: a case report and review of literature," Clinical Lymphoma, Myeloma and Leukemia, vol. 11, no. 5, pp. 379-384, 2011.

[36] D. Ennishi, Y. Maeda, N. Niitsu et al., "Hepatic toxicity and prognosis in hepatitis $\mathrm{C}$ virus-infected patients with diffuse large B-cell lymphoma treated with rituximab-containing chemotherapy regimens: a Japanese multicenter analysis," Blood, vol. 116, no. 24, pp. 5119-5125, 2010.

[37] Y. Tsutsumi, K. Ichiki, S. Shiratori et al., "Changes in hepatitis $\mathrm{C}$ virus antibody titer and viral RNA load in non-Hodgkin's lymphoma patients after rituximab chemotherapy," International Journal of Laboratory Hematology, vol. 31, no. 4, pp. 468-470, 2009.

[38] V. Pitini, G. Sturniolo, C. Arrigo, S. Leonardi, S. Pino, and G. Altavilla, "HCV genotype 2 as a risk factor for reactivation in patients with B-cell lymphoma undergoing rituximab combination chemotherapy: correspondence," British Journal of Haematology, vol. 150, no. 1, pp. 116-118, 2010.

[39] M. Marignani, M. Mangone, M. C. Cox et al., "HCV-positive status and hepatitis flares in patients with B-cell non-Hodgkin's lymphoma treated with rituximab-containing regimens," Digestive and Liver Disease, vol. 43, no. 2, pp. 139-142, 2011.

[40] N. Coppola, M. Pisaturo, S. Guastafierro et al., "Increased hepatitis $\mathrm{C}$ viral load and reactivation of liver disease in HCV RNA-positive patients with onco-haematological disease undergoing chemotherapy," Digestive and Liver Disease, vol. 44, no. 1, pp. 49-54, 2012.

[41] C. Y. Hsieh, H. H. Huang, C. Y. Lin et al., "Rituximab-induced hepatitis $\mathrm{C}$ virus reactivation after spontaneous remission in diffuse large B-cell lymphoma," Journal of Clinical Oncology, vol. 26, no. 15, pp. 2584-2586, 2008.

[42] G. Lake-Bakaar, L. Dustin, J. McKeating, K. Newton, V. Freeman, and S. D. W. Frost, "Hepatitis $\mathrm{C}$ virus and alanine aminotransferase kinetics following B-lymphocyte depletion with rituximab: evidence for a significant role of humoral immunity in the control of viremia in chronic HCV liver disease," Blood, vol. 109, no. 2, pp. 845-846, 2007.

[43] L. Arcaini, M. Merli, F. Passamonti et al., "Impact of treatment-related liver toxicity on the outcome of HCV-positive non-Hodgkin's lymphomas," American Journal of Hematology, vol. 85 , no. 1, pp. 46-50, 2010.

[44] A. Petrarca, L. Rigacci, P. Caini et al., "Safety and efficacy of rituximab in patients with hepatitis $C$ virus-related mixed cryoglobulinemia and severe liver disease," Blood, vol. 116, no. 3, pp. 335-342, 2010.

[45] G. J. Silverman and S. Weisman, "Rituximab therapy and autoimmune disorders: prospects for anti-B cell therapy," Arthritis and Rheumatism, vol. 48, no. 6, pp. 1484-1492, 2003.

[46] S. Ciesek, E. Steinmann, M. Iken et al., "Glucocorticosteroids Increase Cell Entry by Hepatitis C Virus," Gastroenterology, vol. 138, no. 5, pp. 1875-1884, 2010.

[47] M. B. Zeisel, I. Fofana, S. Fafi-Kremer, and T. F. Baumert, "Hepatitis C virus entry into hepatocytes: molecular mechanisms and targets for antiviral therapies," Journal of Hepatology, vol. 54, no. 3, pp. 566-576, 2011.

[48] C. Visco, L. Arcaini, E. Brusamolino et al., "Distinctive natural history in hepatitis $\mathrm{C}$ virus positive diffuse large B-cell lymphoma: analysis of 156 patients from northern Italy," Annals of Oncology, vol. 17, no. 9, pp. 1434-1440, 2006.

[49] N. Coppola, M. Pisaturo, S. Guastafierro et al., "Absence of occult hepatitis $\mathrm{C}$ virus infection in patients under immunosupressive therapy for oncohematological diseases," Hepatology, vol. 54, no. 4, pp. 1487-1489, 2011. 


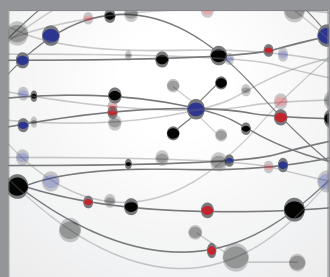

The Scientific World Journal
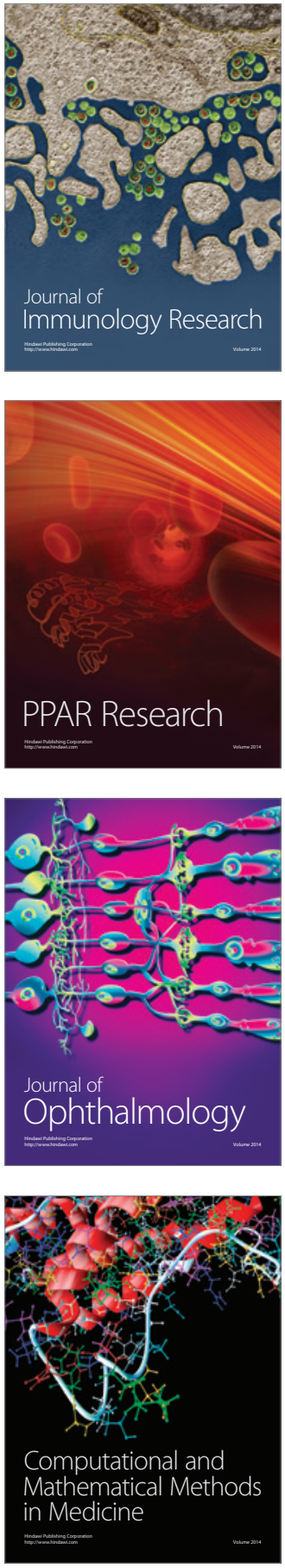

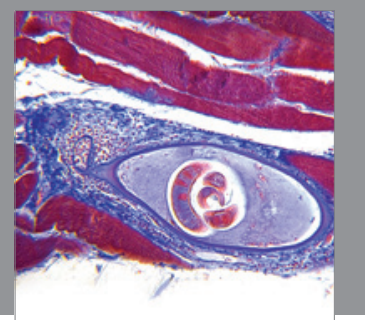

Gastroenterology

Research and Practice
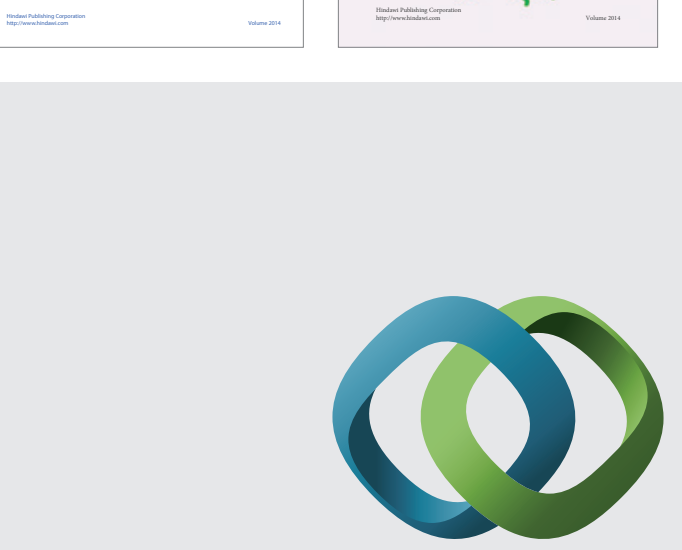

\section{Hindawi}

Submit your manuscripts at

http://www.hindawi.com
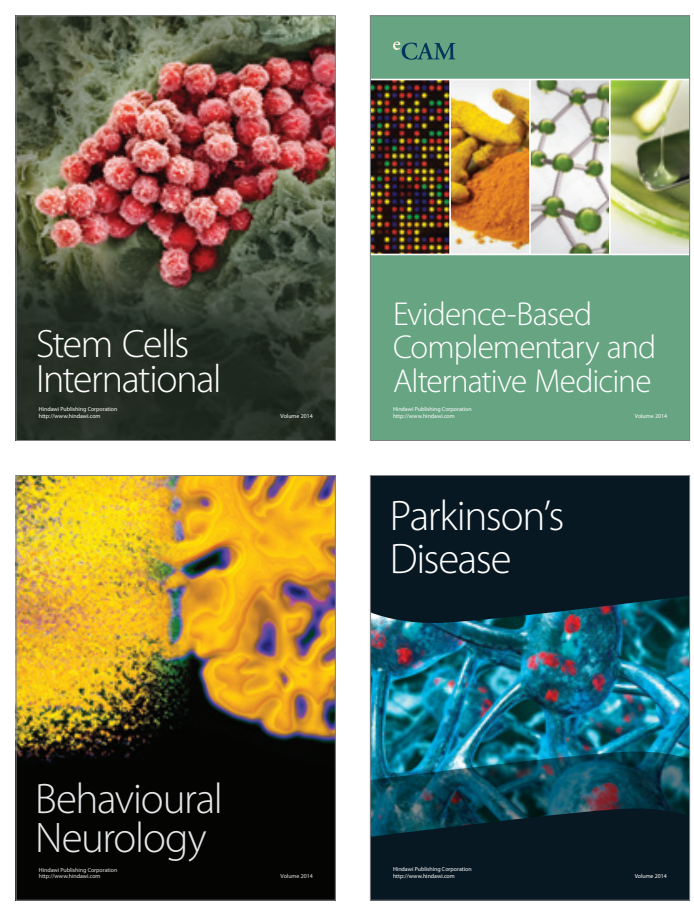

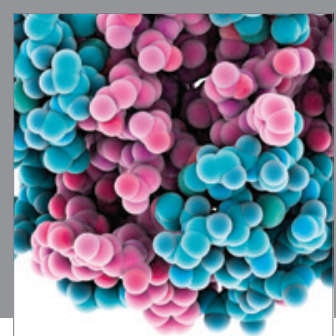

Journal of
Diabetes Research

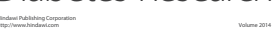

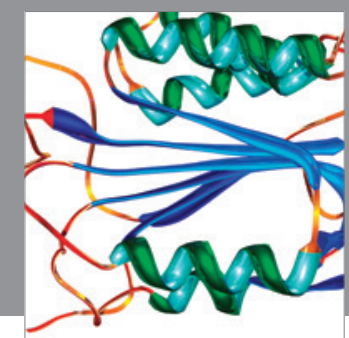

Disease Markers
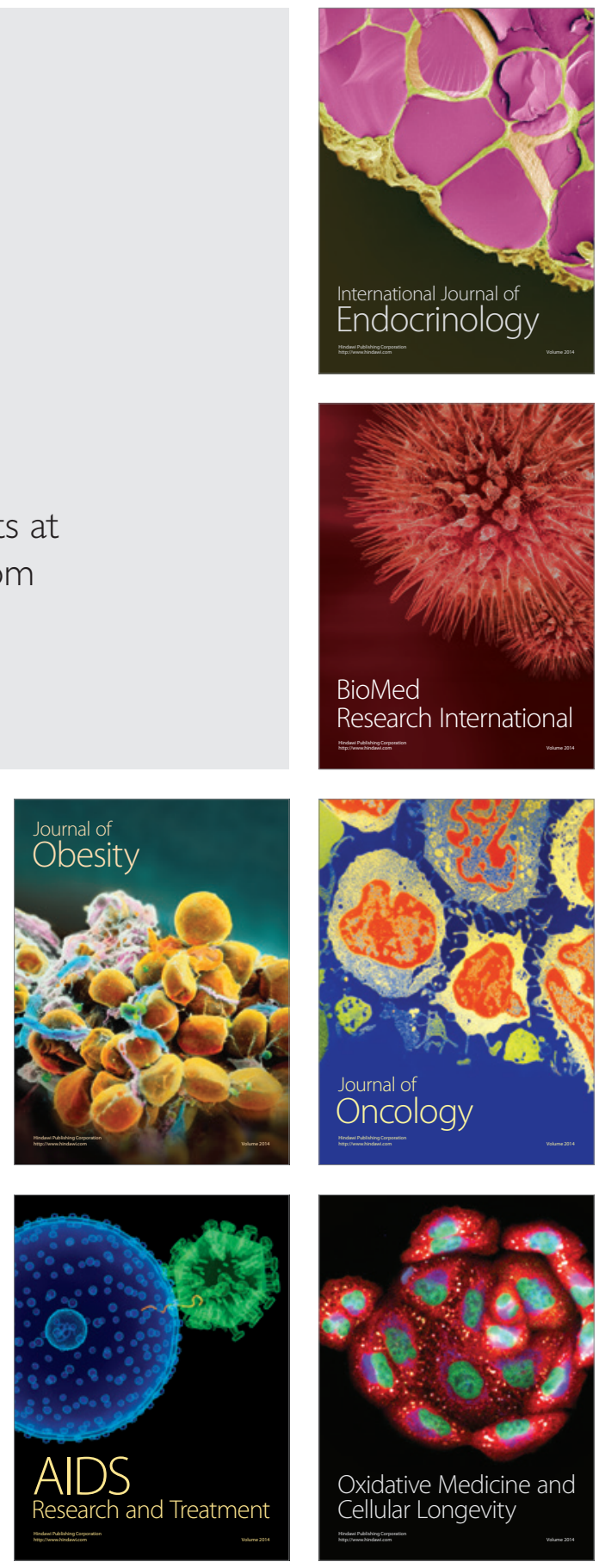